К.С. Каспакбаев Казахский университет путей сообщения Алматы, Казахстан raigul_1980@mail.ru

K.S. Kaspakbayev Kazakh University of Communications Almaty, Kazakhstan

А.Т. Сериккулова Казахский университет путей сообщения Алматы, Казахстан raigul_1980@mail.ru

A.T. Serikkulova Kazakh University of Communications, Almaty, Kazakhstan

А.П. Карпов Казахский университет путей сообщения г. Алматы, Казахстан raigul_1980@mail.ru

A.P. Karpov Kazakh University of Communications Almaty, Kazakhstan

P.C. Устемирова Казахский университет путей сообщения г. Алматы, Казахстан raigul_1980@mail.ru

R.S. Ustemirova Kazakh University of Communications Almaty, Kazakhstan

А.А. Асанов К КУСТА им. Н.Исанова Бишкек, Кыргызская Республика

Asanov52@mail.ru

A.A. Asanov KSUCTA n.a. N. Isanov Bishkek, Kyrgyz Republic

ФОРМИРОВАНИЕ СОСТАВА НА ЖЕЛЕЗНОДОРОЖНОМ ПУТИ С РАЗЛИЧНОЙ КОЛЕЕЙ

\title{
FORMATION OF THE COMPOSITION ON THE RAILWAY TRACK WITH A DIFFERENT GAUGE
}

Казакстандын экономикасын өнүктүрҮҮнүн азыркы этабында, эл аральк соода мамилелерин күчөтҮY (анын ичинде алыскы чет өлкөлөр менен) экономикалык саясаттын негизги милдеттердин бири болуп саналганы менен анын ийгиликтүҮ чечилүүсү өлкөдө ишке ашырыльп жаткан реформалардын натыйжасынан көз каранды. Эл аральк поезддер бир нече кошкучтар жана дөңцәлөк алмаштыруу натыйжасында станцияда туруу менен убактысын жолдо 3 саатка чейин текке кетирүүгө дуушар болуп жатат. XX кылымдын башында, вагондордун колеяларын туурасынын өзгөртүҮ аракеттери иштелипп чыгууда.

өзөк сөздөр: кыймылдуу курамы, вагон, темир жол, дөнгелөк түгөйү, курамы, вагондун кузову, темир жол.

На современном этапе развития экономики Казахстана, укрепление международных торговых связей (в том числе и со странами дальнего зарубежья) - одна из главньх задач экономической политики, от успешного решения которой во многом зависит результат осуществляемых в республике реформ.

$B$ результате многократных сцепок-расцепок $u$ замены колесных тележек международные поезда на станщии могут находится до $3 x$ часов теряя время в пути.В начале XX века начались попытки разработки технологии перехода вагонов с одной ширины колеи на другую, и обратно. Более прогрессивным способом стала перестановка тележек пассажирских и грузовых вагонов для разной ширины колеи в специильно организованных пунктах перестановки тележек на пограничных стыках (ППВ). Для своевременного формирования на территории Казахстана конкурентоспособного международного транспортного коридора необходимо предусмотреть различные варианты решения существующих проблем, в том числе связанных с движением поездов на участках с 
различной шириной рельсовой колеи, в том числе имеются разработки конструкций раздвижной колесной пары от казахстанских специалистов.

Ключевые слова: подвижной состав, вагон, рельс, колесная пара, состав, кузов вагона, железнодорожный путь.

At the present stage of development of the economy of Kazakhstan, the strengthening of international trade relations (including with foreign countries) is one of the main tasks of economic policy, the successful solution of which largely determines the result of the reforms implemented in the country.

As a result of multiple couplers, uncoupling and replacement of wheeled carts, international trains at a station can be up to 3 hours losing travel time. At the beginning of the twentieth century, attempts were made to develop the technology of moving cars from one gauge to another, and vice versa. A more progressive way was the rearrangement of carriages of passenger and freight cars for different gauge widths in specially organized permutation stations of carriages at border junctions (PPV). For the timely formation of a competitive international transport corridor on the territory of Kazakhstan, it is necessary to foresee various options for solving existing problems, including those associated with train traffic on sections with different track gauges, including designs of a sliding wheelset from Kazakhstani specialists.

Key words: rolling stock, car, rail, wheel pair, composition, car body, railway track.

Введение. Железнодорожный транспорт является одним из самых важных регуляторов социально-политической и экономической жизни каждого государства.

На современном этапе развития экономики Казахстана, укрепление международных торговых связей (в том числе и со странами дальнего зарубежья) - одна из главных задач экономической политики, от успешного решения которой во многом зависит результат осуществляемых в республике реформ. Поднять производительность существующих железнодорожных линий можно за счет увеличения пропускной способности и снижения времени доставки грузов.

Для своевременного формирования на территории страны конкурентно-способного международного транспортного коридора необходимо предусмотреть различные варианты решения существующих проблем, в том связанных с движением поездов на участках с различной шириной рельсовой колеи.

В настоящее время при необходимости смены ширины колеи железнодорожного состава используется способ замены ходовых тележек, который характеризуется существенными потерями на непроизводительные операции.

Материалы и методы. Так, в настоящее время, территория России связывается с железными дорогами стран Европы только через один пограничный переход в Бресте. Там же производится и переход с одной колеи на другую путем смены колесных тележек с колесными парами разного стандарта.

Поезд по российской колее 1520 направляется в цех перестановки колесных пар куда его закатывают с одной стороны (рис.1).

В цеху установлены домкраты и насквозь проходит колея российского стандарта 1520. С другой стороны цеха колея сужается до 1435.По одной и той же (широкой) колее могут двигаться на низкой скорости тележки и стандарта 1520 и 1435, при этом колесные пары 1520 лежат на рельсе всей шириной колеса, а 1435 касаются только внешним краем ширины колеса - внутренняя часть с ребордой висит в воздухе.

Для того чтобы колесная пара стандарта 1435 не соскользнула с рельса, внутри колеи 1520 проложены контррельсы. Контррельсы и подпирают изнутри колесные пары 1435 со стороны реборды не давая произойти сходу колес (рис.2).

В цеху установлены домкраты и насквозь проходит колея российского стандарта 1520. С другой стороны цеха колея сужается до 1435.По одной и той же (широкой) колее 
могут двигаться на низкой скорости тележки и стандарта 1520 и 1435, при этом колесные пары 1520 лежат на рельсе всей шириной колеса, а 1435 касаются только внешним краем ширины колеса - внутренняя часть с ребордой висит в воздухе.

Для того чтобы колесная пара стандарта 1435 не соскользнула с рельса, внутри колеи 1520 проложены контррельсы. Контррельсы и подпирают изнутри колесные пары 1435 со стороны реборды не давая произойти сходу колес (рис.2).



Рис.1. Маневровый локомотив закатывает состав

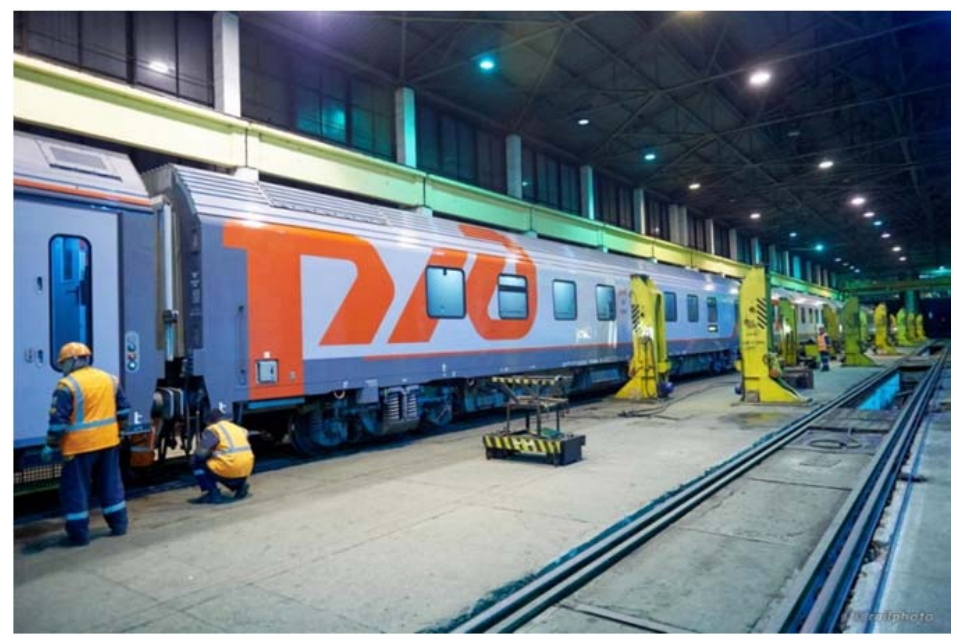

Рис.2. Процесс расцепки состава

Весь процесс только в цеху занимает около часа. Одновременно переставить могут до 12 вагонов в составе.

В результате многократных сцепок-расцепок и замены колесных тележек международные поезда по станции Брест могут находится до 3 часов, теряя время в пути.

Результаты исследования. В начале XX века начались попытки разработки технологии перехода вагонов с одной ширины колеи на другую, и обратно. Более прогрессивным способом стала перестановка тележек пассажирских и грузовых вагонов для разной ширины колеи в специально организованных пунктах перестановки тележек на пограничных стыках (ППВ). В Казахстане пункт перестановки вагонов организован на станциях Достык и Хоргос на границе с Китаем (Рис.3 и 4).

Так, на станции Достык пункт перестановки вагонов (ППВ)предназначен для перестановки пассажирских и грузовых вагонов колеи 1520 мм на колею 1435 мм и наоборот.

Кроме того, на ППВ производится ремонт вагонов, единая техническая ревизия тележек, текущий их ремонт и подготовка их для подкатки под вагоны, погрузка тележек и 
колесных пар для отправки последних на плановые виды ремонта, выгрузка после ремонта планово-предупредительный ремонт и обслуживание оборудования и устройств.

Работа пункта перестановки грузовых вагонов организована вахтовым методом круглосуточно, в две смены по 12 часов.

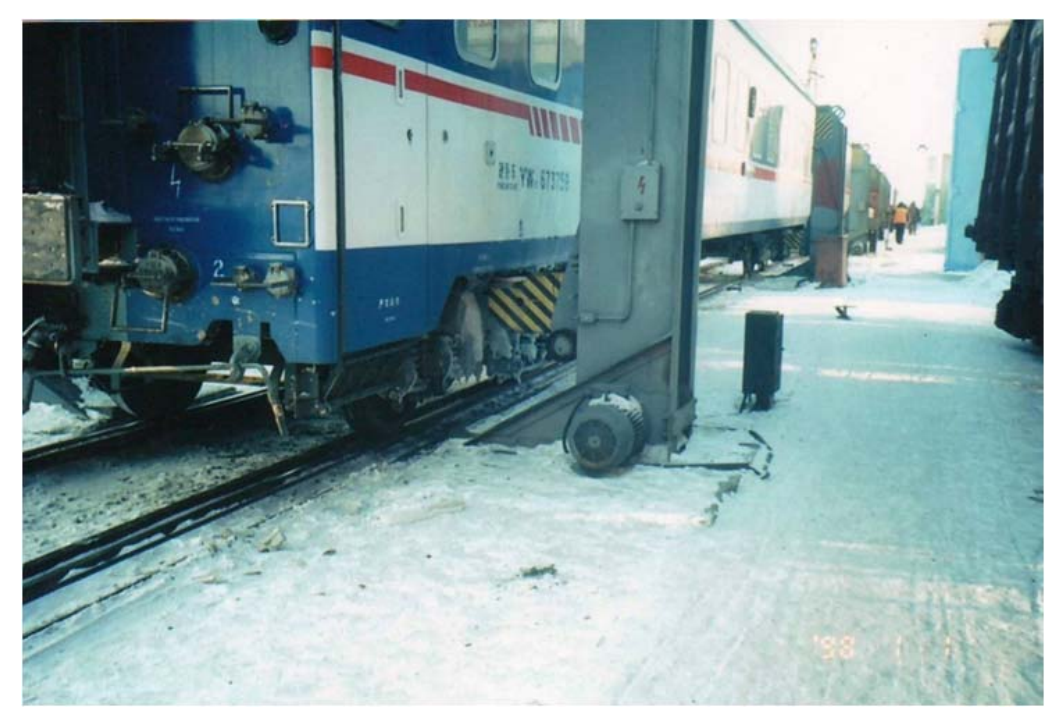

Рис.3. Смена тележек пассажирского вагона

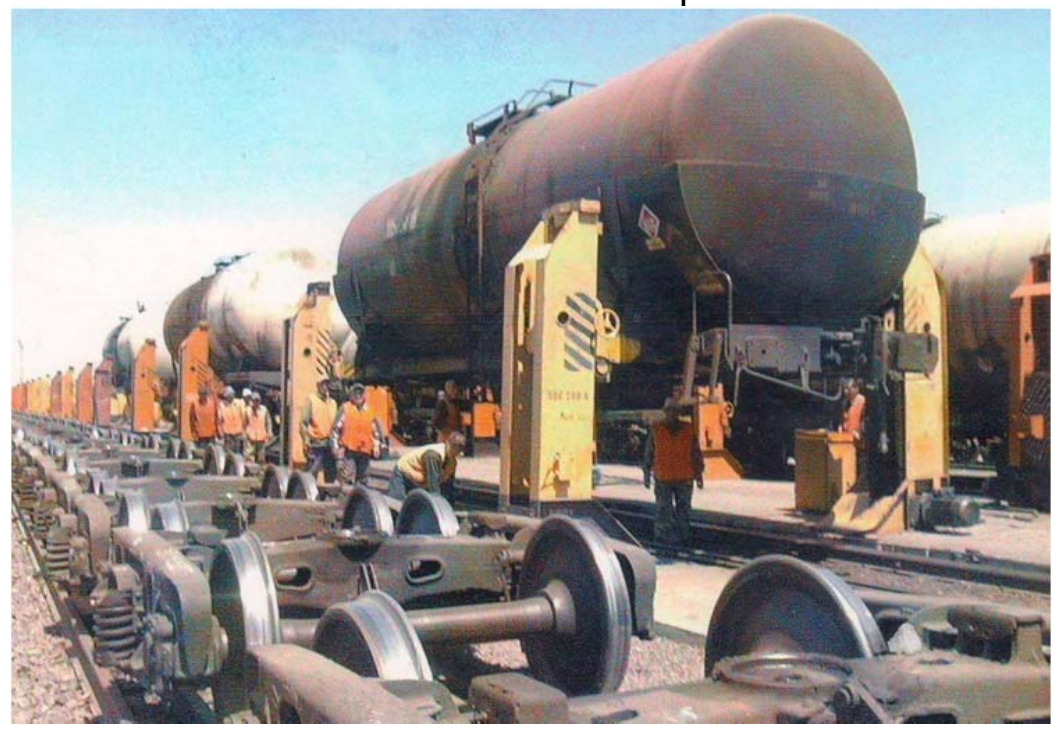

Рис.4. Смена тележек грузового вагона

Технологический процесс включает следующие основные операции:

- информацию о прибытии на станцию груженых вагонов подлежащих перестановке с колеи 1520 мм на колею 1435 мм, а также порожняка для перестановки с колеи 1435 мм на колею 1520 мм;

- подборка и подача вагонов со станции на путь ППВ;

- полномерное описание вагонов;

- подборка тележек;

- расстановка вагонов по позициям;

- смена тележек;

- соединение вагонов, опробование автотормозов и уборка их с перестановочного пути.

Согласно графику технологического процесса на перестановку грузового вагона уходит 102 мин, а пассажирского - 71 мин. 
После расстановки вагонов по позициям сразу же начинаются подготовительные работы к подъемке вагонов.

В эти работы входит:

- подклинивание тележек, разъединение тяг тормозной рычажной передачи, выемка шкворней, демонтаж карданного вала с приводом генератора от средней части оси соединение силового кабеля генератора, выдвижение хоботов домкратов.

Подъемка кузова вагона производится одновременно четырьмя электро домкратами грузоподъемностью 40-50 тн.

Подъемка вагонов начинается сразу после окончания подготовительных работ. После подъемки вагонов на всех позициях и обеспечения габарита, с помощью лебедки производится уборка тележек из-под вагонов.- Подкатка тележек другой колеи под вагоны производится также при помощи лебедки. После опускания кузова производятся все работы предшествующие подъемке в .обратном порядке. Кроме смены тележек у головного и хвостового вагонов производится смена автосцепного устройства с изменением высоты над уровнем головок рельсов.

Переставленные вагоны по техническому состоянию должны удовлетворять требованиям и нормам установленным « Правилами технической эксплуатации» и «Правилами пользования вагонами в международном пассажирском и железнодорожном грузовом сообщении (ППВ)».

В настоящее время способ замены ходовых тележек характеризуется существенными потерями времени на непроизводительные операции.

Перестановка тележек вагонов с колеи $1520 \mathrm{~mm}$ на $1435 \mathrm{~mm}$ и на оборот на перестановочных пунктах вблизи пограничных станций, имеет существенные недостатки увеличение времени оборота вагонов; существенные затраты технологических и производственных ресурсов.

Особенно эффективным методом прохождения подвижным составом системных стыков рельсовой колеи считается использование раздвижных колесных пар.

Поэтому актуальной является проблема разработки раздвижных колесных пар, способных без остановки движения изменять ширину колеи на специальных переводных путевых устройствах. При этом должна обеспечиваться почти абсолютная надежность, поскольку отказ раздвижной колесной пары приводит к аварийным с тяжелыми последствиями.

В 1969 году впервые началось практическое применение раздвижных колесных пар. Тогда из Барселоны в Женеву прибыл первый пассажирский поезд TalgoRD испанского производства с раздвижными колесными парами [1].

Ещё в 1965 году испанская фирма Talgo начала разрабатывать системы автоматической перестановки колес.

Надежную работу показывает конструкция испанской фирмы «Тalgo». Раздвижные колесные пары эксплуатируются на пассажирских экспрессах, разработанных этой же фирмой. Они курсируют между Испанией (где ширина колеи 1676мм) и странами Европы (1435 мм) и работают безаварийно десятки лет. Поезда TALGO поставлены на одноосные тележки (то есть рессорное подвешивание, тормозное и другое оборудование смонтированы на одной раздвижной колесной паре). Чтобы при этом нагрузка на каждую ось не превышала допустимой нормативами, длина каждого вагона меньше, чем стандартного пассажирского 4осного вагона.

Операция по переходу на другую ширину колеи выполняется автоматически без помощи персонала в процессе прохождения поезда на скорости $10-15$ км/ч по специальному переводящему устройству, исполненному в виде узла рельсовых путей (рис.5) [2]. 


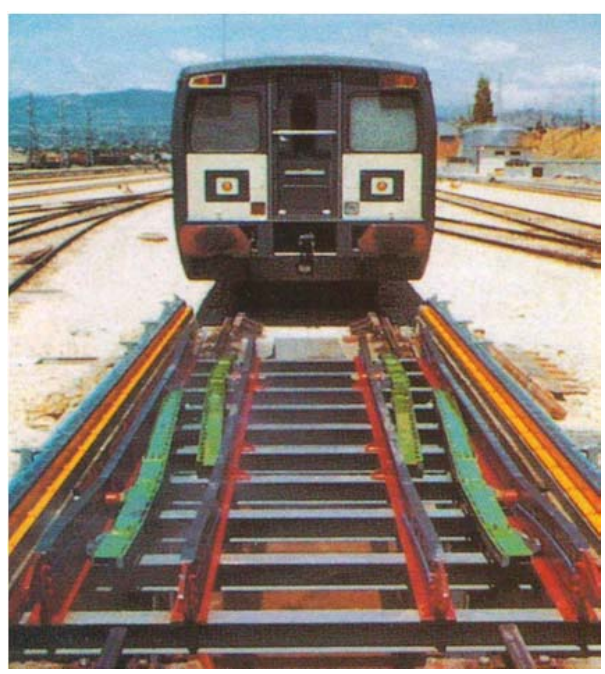

Рис.5. Схема узла рельсовых путей системы Talgo для смены колеи

Схема раздвижной колесной пары «Talgo» показана на (рис.6). В связи с симметрией на схеме обозначены детали левой половины - левая полуось вращается вбуксом подшипнике и внутреннем подшипнике. Оба подшипника соединены горизонтально размещенной стальной жесткой рамой. Каждая колесная пара несет на себе две таких вспомогательные рамы. Зато колесо соединено с полуосью обычной посадкой с натягом. При изменении ширины колеи детали перемещаются совместно.

Пассажирских вагонов лежит принудительное поперечное смещение колесных блоков, которое происходит при движении вагона по переводной установке. Передвижение колес происходит в загруженном состоянии (рис.6). Снятие нагрузки происходит за счет того, что опоры скольжения, расположенные с внешней стороны подшипников, надвигаются на поддерживающие рельсы переводной установки и перемещаются по ним.

Процесс можно разбить на пять отдельных этапов:

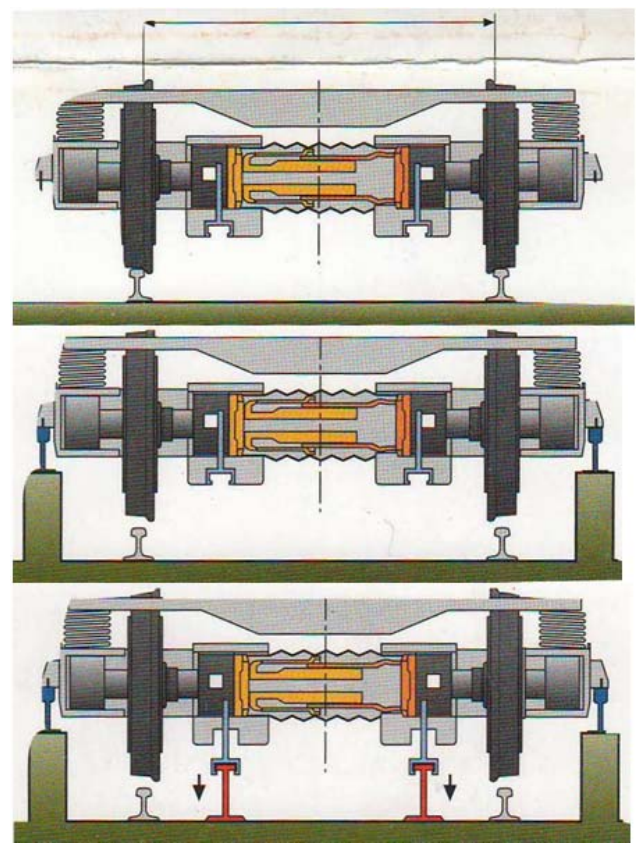

1. Освобождение колес.

Нагрузка переходит на внешние направляющие скольжения

2. Разблокировка колес от бокового ограничителя. 


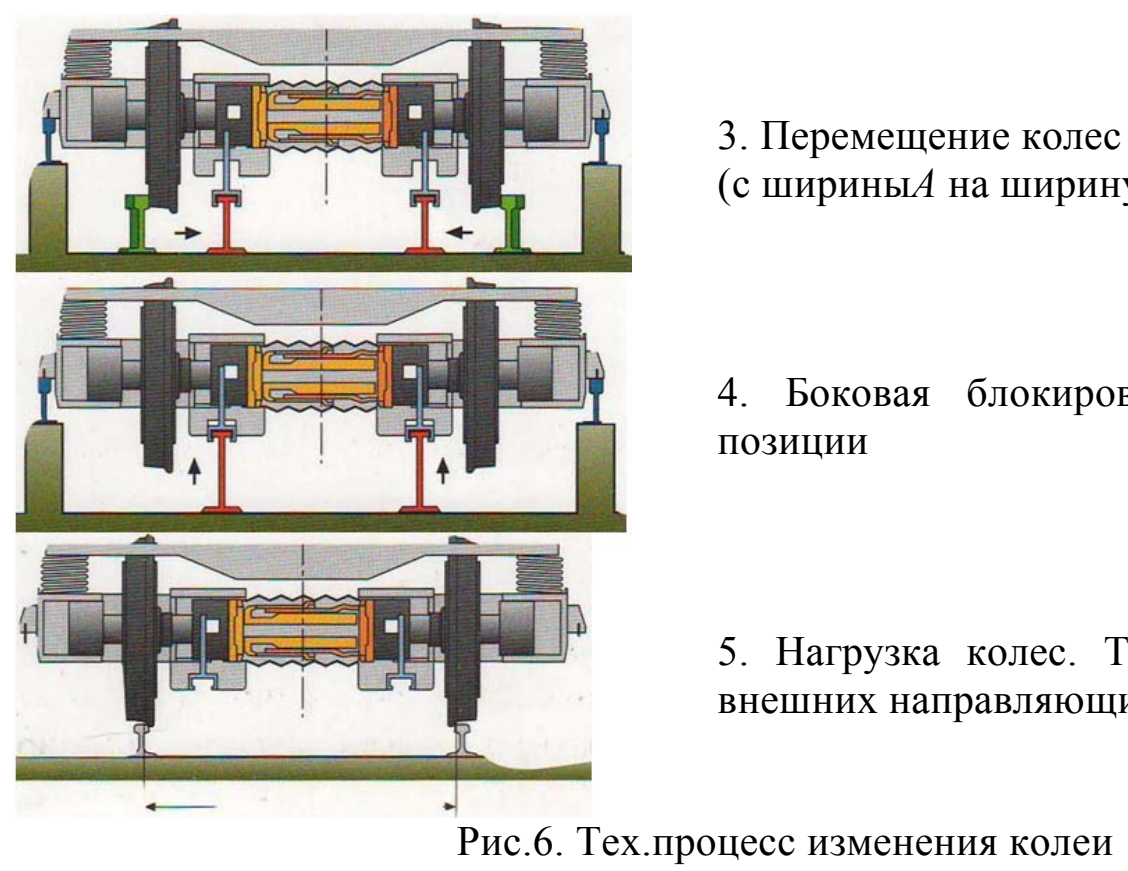

При этом Т-образные направляющие стационарной установки заходят в соответствующие пазы блокирующих устройств колесных узлов и вытягивают замки крепления подшипников, и колеса вместе с подшипниками высвобождаются. Направляющие рельсы установки сходятся, воздействуя на наружные грани ободов колес, и сдвигают их в поперечном направлении к оси в положение, соответствующее ширине новой колеи.Т-образные направляющие вновь заходят в пазы блокирующих устройств. Замки крепления подшипников возвращаются на место, после чего в новом положении фиксируются колеса. Плавно уменьшается высота поддерживающих рельсов, и скользящие упоры сходят с них, колеса опускаются на рельсы. Таким же образом процесс происходит в обратном направлении.

Аналогичную систему автоматического перехода Talgo разработала и для грузовых вагонов. Конструкция колесной пары с раздвижными колесами для установки на тележки типа Y21 широко применяется на грузовых вагонах Испании. На рис. 7 изображен общий вид колесной пары с обозначениями его частей [3].

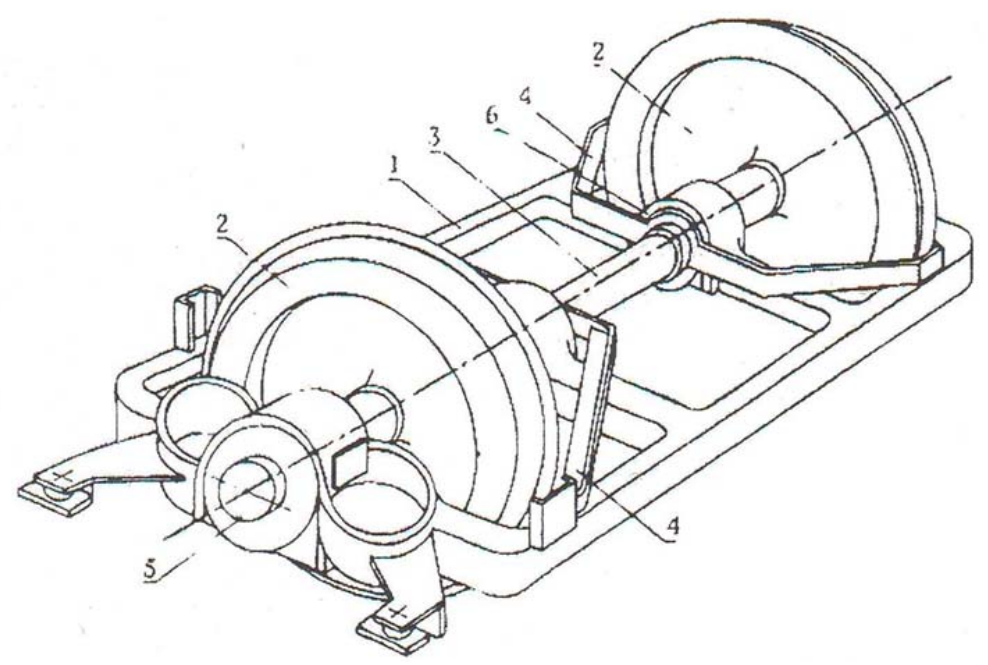

Рис.7. Колесная пара системы Talgo

1 - рама; 2 - колесные блоки; 3 - соединительное устройство; 4 - механизм перемещения башмаков; 5 - буксы; 6 - устройство контроля температуры. 
Для своевременного формирования на территории Казахстана конкурентоспособного международного транспортного коридора необходимо предусмотреть различные варианты решения существующих проблем, в том числе связанных с движением поездов на участках с различной шириной рельсовой колеи, в том числе имеются разработки конструкций раздвижной колесной пары от казахстанских специалистов. В [4] приведена разработанная конструкция раздвижной колесной пары для железнодорожного транспортного средства, с участием одного из авторов.

Это достигается тем, что в раздвижной колесной паре для железнодорожного транспортного средства, включающего: ось, два колеса, которые установлены с возможностью перемещения вдоль оси, фиксации на ширине заданной колеи, блокирования от случайного осевого перемещения, для смены колеи и передачи на ось крутящего момента, узлы фиксации колес с фиксирующими сухарями и узел передачи крутящего момента, ось выполнена из двух полуосей, соединенных муфтой с возможностью взаимного осевого перемещения (рис.8)

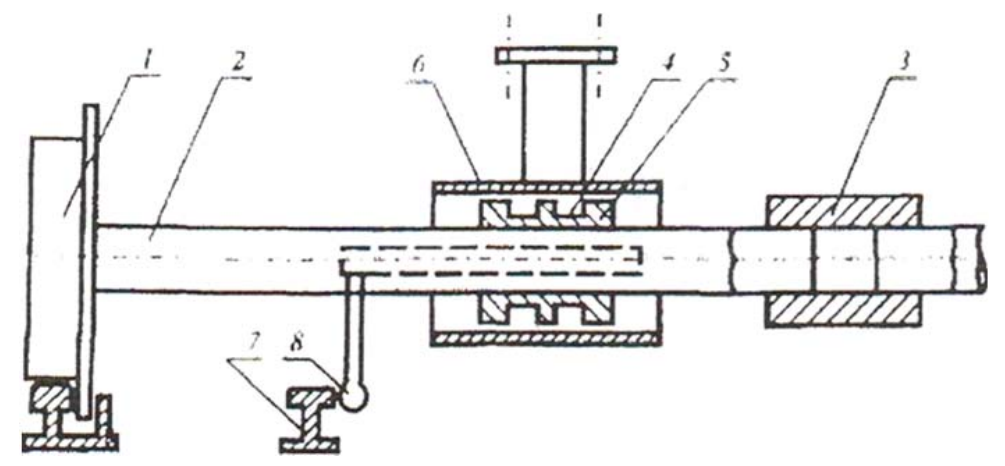

Рис.8. Схема колесной пары: 1 - колесо; 2 - полуоси; 3 - муфта; 4 - кольцевые канавки; 5 - втулка; 6 - корпус узла фиксации; 7 - направляющие для приводной головки;

$$
8 \text { - приводная головка. }
$$

Устройство для смены колеи заявленной раздвижной колесной пары выполнено в виде рельсового узла, однако в отличие от других систем раздвижных колесных пар конечные участки рельсовых путей широкой и узкой колеи соединены симметрично изогнутыми рельсами в единый рельсовый путь (рис.9). При этом соединяющие рельсы выполнены с возможностью воздействовать на гребни колес для их осевого перемещения, а направляющие рельсы для разблокировки колес изогнуты в горизонтальной плоскости и установлены с возможностью оказания давления на разблокирующие элементы, направленные вдоль оси колесной пары. Кроме того узел включает еще две пары изогнутых рельсов, являющихся направляющими для приводной головки разблокировочной вилки при перемещениях вилки с целью разблокировки или фиксации колес [5].

Раздвижная колесная пара включает два колеса, жестко скрепленные с полуосями. Полуоси формируют единую ось путем соединения их концов муфтой. Концы полуосей располагаются в муфте с возможностью их ограниченного осевого перемещения и передачи крутящего момента, для чего отверстие муфты и концевые участки полуосей выполняются с фигурным профилем, например, в форме квадрата, или шестигранника, или в виде элементов шлицевого соединения [6].

Выполнение узла фиксации колес с сухарями, перемещение которых обусловливается горизонтальными усилиями, делает конструкцию этого узла и всей колесной пары простой и надежной. Приведенная система позволяет перевозить пассажиров и грузы в соответствующих типах вагонов, не меняя тележки при движении в различной железнодорожной колее. 


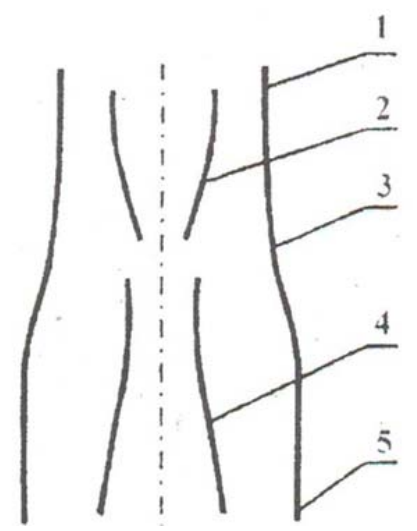

Рис. 9. Схема узла рельсовых путей для смены колеи: 1 - узкая колея;

2,4 - направляющие для приводной головки; 3 - промежуточный участок; 5 - широкая колея.

Выводы и обсуждение. Таким образом, применение колесных пар автоматически меняющие ширину колеи имеет большую перспективность, при соблюдении выдвинутых условий. Технология позволит внушительно снизить время пребывания пассажирских составов в пути. Однако перед использованием той или иной системы требуется учитывать много важных нюансов. Во-первых, всем работникам, кроме конструктивной сложности, свойствинен один недостаток - стандарты профилей поверхности катания колес, рабочих поверхностей головок рельсов, под уклона рельсов колеи 1520 мм и колеи 1435 мм не соответствуют друг другу, то есть различаются. Во-вторых, следует учитывать габариты железнодорожного подвижного состава и приближения строений тех стран, где предполагается эксплуатация вагонов с раздвижными колесными парами. Помимо этого, прежде чем начинать широко внедрять ту ли иную систему, требуется осуществить совокупность мер для гарантирования безопасной эксплуатации новых ходовых частей. Будет необходимо организация специализированной базы более высокого уровня для технического обслуживания и ремонта систем раздвижных колесных пар, чем для обычных. Стоимость постройки и обслуживания таких систем безусловно превысит аналогичные затраты для традиционных систем. Но расчеты показывают, что с экономической точки зрения использование таких систем может быть вполне оправдано.

\section{Список литературы}

1. Изменение ширины колеи по системе Talgo в тележках грузовых вагонов[Текст] / Железные дороги мира. - 1995. - №4. - С. 32-38.

2. P.Nicolae, C.Plescan, I.Szentes, M.Bolanu C.Sima, D.Mitu, G.Dumitru. Newechnologies of gauge variation for wheelset vechilescrossing // Bulletin of the Transilvania University of Braasov.2015. №8. C. 248-250.

3. Садчиков П.И. Технология перехода железнодорожного подвижного состава с одной колеи на другую (международный опыт) [Текст] / П.И. Садчиков, О.Л. Целишева // Техника железных дорог. - 2014. - №12. - С.27-28.

4. Патент Республики Казахстан №16081, Кл.B61F 7//00, 2005. бюлл. №8.

5. Каспакбаев К.С. Раздвижная колесная пара железнодорожного вагона [Текст] / К.С. Каспакбаев, М.А. Шакенов // Промышленный транспорт Казахстана. - 2005. - №4. - С. 1315.

6. Курган Н. Повышение интероперабельности в международном железнодорожном сообщении Австрия - Словакия - Украина -Россия [Текст] / Н. Курган, Е. Возная // Украінськізалізниці. - 2014. - №12. - С.27-28. 